\title{
NORMATIVE VALUE OF MAXIMAL STATIC RESPIRATORY PRESSURES IN HEALTHY CHILDREN BETWEEN AGE GROUP 8-12 YEARS
}

\author{
Drashti Talati ${ }^{1}$, Prem V ${ }^{1}$, Suruliraj Karthikbabu ${ }^{1}$, and Pratiksha Rao ${ }^{1}$ \\ ${ }^{1}$ Manipal Academy of Higher Education
}

June 1, 2020

\begin{abstract}
Background: The maximal static respiratory pressure (MRP) assessment is vital for both clinical reasoning and respiratory system growth and development. The predicted normal values of maximal inspiratory pressures (PImax) and maximal expiratory pressures (PEmax) published for the western population may not be appropriate for Indian children because of the ethnic difference and large inter-subject variations of PImax and PEmax values. Objective: The purpose of the study was to establish normative values of MRP in healthy children aged 8-12 years. Methods: A cross-sectional study was conducted among nine government and public schools of Bangalore, India. We assessed the anthropometric measures (height, weight, BMI, waisthip ratio, pulmonary function tests) and MRP for 887 children (490 boys and 397 girls) following guidelines by American Thoracic Society/European Respiratory Society. Results and conclusion: The mean of PImax and PEmax were 60.83+19.5 and $62.26+18.13 \mathrm{cmH} 2 \mathrm{O}$, respectively. The mean of PImax was relatively lower by mean of $15.32 \mathrm{cmH} 2 \mathrm{O}$ when compared from Brazilian, $12.2 \mathrm{cmH} 2 \mathrm{O}$ from Mexican, and $16.23 \mathrm{cmH} 2 \mathrm{O}$ from the Australian population. Similarly, the mean of PEmax of the current study was relatively lower by mean of $27.625 \mathrm{cmH} 2 \mathrm{O}$ when compared from Brazilian, $21.845 \mathrm{cmH} 2 \mathrm{O}$ from Mexican, and $24.365 \mathrm{cmH} 2 \mathrm{O}$ from the Australian population. This states that ethnicity has a strong influence on respiratory muscle strength. Thus, the study provides the normative data for maximal static respiratory pressures for healthy children aged 8-12 years in Bangalore, India
\end{abstract}

\section{Introduction:}

Respiratory muscle strength reflects the function of respiratory muscles ${ }^{1}$. Maximal static inspiratory $\left(\mathrm{PI}_{\max }\right)$ and expiratory $\left(\mathrm{PE}_{\max }\right)$ mouth pressures, the simplest measures of respiratory muscle strength, play an important role in evaluating the extent and severity of respiratory muscle weakness ${ }^{2}$. Among children, these measures are being used in rehabilitation programs to determine the respiratory muscle strength after the treatment and for successfully weaning children from mechanical ventilation systems ${ }^{1,3,4}$.

Several studies established reference values for respiratory muscle strength both in children and adolescents have shown great interindividual variability ${ }^{1}$. This has been attributed to differences in geographical, social, and anthropometric variables or variability of equipment and techniques employed ${ }^{5}$. The predicted equations available in the literature, demonstrate that the variables age ${ }^{6-11}$, height ${ }^{6,9,11}{ }^{\text {weight }}{ }^{9,10}$, and gender ${ }^{1}$ contribute to differences in lung recoil, airway-alveolar differential growth, chest wall compliance and dimensions influencing the respiratory muscle strength ${ }^{1,5}$.

Previous studies ${ }^{12,13}$ have stated that the respiratory muscle strength varies significantly when compared to Caucasian children inferring that because of large variability between population the normative values derived in the western population may not be suitable for the Indian population. However, there is no published data on respiratory muscle strength in the south-Indian children. Therefore, the present study 
aimed to measure maximal static respiratory pressure in children aged 8-12 years and to derive the normative values for clinical practice.

\section{Material and Methods:}

\section{Recruitment}

A time-bound cross-sectional study was conducted from July 2019 - March 2020. The study protocol was approved by the Institutional Research Committee. The study was registered under the clinical trial registry India (number: CTRI/2019/08/020512). Additionally, the district health officer, district education officer, and block education officer were approached to seek their permission before testing and gathering data.

The list consisting of a total of fifty-one schools was obtained from the authorities. The principals of twenty-three government, local, public, and aided schools were approached conveniently for the conduction of the study within the school premises. Out of which nine schools permitted conducting the study within the school premises. All parents or legal guardians of the children aged 8-12 years of those respective nine schools received a letter explaining the study along with the written informed consent form and the questionnaires consisting of the overall health status, physical activity, and diet and lifestyle of the child.

The children eligible to participate in the study were children between the age group 8-12 years of both genders, enrolled in government, local public, and aided schools in urban Bangalore, India, and able to understand and perform the procedure. The children who had cardio-respiratory disorders; congenital malformation of the respiratory tract; recent respiratory tract infection, cold and/or cough, and recurrent upper airway infection in the four previous weeks and those children without the informed written consent by parents and/or legal guardians were excluded.

A demographic and family health questionnaire gathering information regarding personal and family health status. A diet and lifestyle questionnaire were given to gather information regarding transportation to school, activities performed, television (TV) time, TV in the bedroom, quality and quantity of sleep, perception of health, and $\operatorname{diet}^{14}$. The test-retest reliability was ranging from $0.37-0.78$ and gross miss-classification for all four groups was $<5 \%{ }^{15,16}$. A Short form- international physical activity questionnaire (IPAQ) gathers information regarding total sitting time ( $\mathrm{min} /$ day) during one day of the week and the total sitting time on the weekend. Children were evaluated according to the frequency and duration of moderate and vigorous physical activity and any walking done for at least ten minutes in the last week ${ }^{17,18}$. The test-retest intraclass-correlation of moderate physical activity, vigorous physical activity, and moderate to vigorous physical activity range from $0.73-0.95(\mathrm{P}<0.001)^{19}$. These 3 questionnaires filled up by the parents after giving the consent.

\section{Measurements:}

All the measurements were taken within the school premises during the regular school course and without disturbing the regular schedule of the school by a single investigator between 9 am- 4 pm.

Height, waist, and hip circumference and weight were measured following the standard procedure with a precision of $0.5 \mathrm{~cm}, 0.1 \mathrm{~cm}$, and $100 \mathrm{~g}$ respectively, and waist and hip circumference were measured. Body mass index (BMI) $\left(\mathrm{kg} / \mathrm{m}^{2}\right)$ was calculates as: body weight (in $\left.\mathrm{kg}\right) /(\text { height })^{2}$ (in meters ${ }^{2}$ ).

Forced vital capacity $(\mathrm{FVC})$, forced expiratory rate in $1^{\text {st }}$ second $\left(\mathrm{FEV}_{1}\right)$, and $\mathrm{FVC} / \mathrm{FEV}$ 年ere recorded using a portable handheld digital spirometer with the excellent inter-rater reliability $(>0.75)^{20}$ and following American Thoracic Society/European Respiratory Society guidelines ${ }^{21}$. A resting period of 1 minute was allowed between each FVC, $\mathrm{FEV}_{1}$, and $\mathrm{FVC} / \mathrm{FEV}_{1}$ manoeuver. The manoeuver was stopped with a minimum of 3 and a maximum of 8 manoeuvers were concluded. The best of the values for each $\mathrm{FVC}, \mathrm{FEV}_{1}$, and $\mathrm{FVC} / \mathrm{FEV}_{1}$ maneuver was taken into consideration for analysis.

The maximal respiratory pressures (MRP) using a handheld manometer MicroRPM (Care Fusion, San Diego, California, USA) following American Thoracic Society/European Respiratory Society guidelines ${ }^{22}$. The reliability with interclass correlation coefficient for the device was $0.86-0.90^{23}$. The device was connected to 
a semirigid and flat from the upper portion mouthpiece with wings in its extremes ensuring good adjustment to the lips and to avoid an increase in intra-oral pressure caused by contraction of buccinator muscles.

The children were instructed to exert maximum inspiratory effort starting from the residual volume for assessment of maximal inspiratory pressure $\left(\mathrm{PI}_{\max }\right)$ and were asked to exert maximum expiratory effort starting from total lung capacity for assessment of maximal expiratory pressure $\left(\mathrm{PE}_{\max }\right)$. A resting period of 1 minute was allowed between each $\mathrm{PI}_{\max }$ and $\mathrm{PE}_{\max }$ maneuver. The maneuver was stopped with a minimum of 3 and a maximum of 5 maneuvers were concluded. The best of the values for each $\mathrm{PI}_{\max }$ and $\mathrm{PE}_{\max }$ maneuver was taken into consideration for analysis.

Measurement for pulmonary function test (PFT) and MRP were taken in sitting with back against the chair, head in a neutral position, chest forming $90^{\circ}$ with their hips and arms resting on lower limbs, and wearing a nose clip to avoid the air leakage. Maneuvers were verbally explained and visually demonstrated by the investigator before gathering test data. Verbal encouragement was given whenever necessary because these are an effort-dependent test.

\section{Statistical Analysis:}

Data were analyzed using SPSS statistics software version 22.0, with a significance level of $5 \%$. Data normality was verified by the Shapiro Wilkins test. Descriptive statistics were expressed as the mean and standard deviation. One-way analysis of variance (ANOVA), followed by Tukey's post hoc test, was used to determine whether there was a significant difference in the maximal respiratory pressures between the 5 ages assessed. Non-paired Student's t-test was applied to verify inter-gender differences. The $3^{\text {rd }}, 10^{\text {th }}$, $25^{\text {th }}, 50^{\text {th }}, 75^{\text {th }}, 90^{\text {th }}$, and $97^{\text {th }}$ smoothing percentiles were chosen by gender and age for reference values. The lower limit of normal (LLN) was calculated by subtracting a value two times greater than the standard deviation of the measurements from mean maximal respiratory pressures.

\section{Result:}

A total of 1344 questionnaires were handed out at 9 participating schools. Of the 895 that were returned, 8 children were not included in the study based on inclusion and exclusion criteria. Results from the remaining 887 children ( 290 boys and 397 girls) were analyzed in the study with the mean age for boys being $9.86+$ 1.26 and for girls being $9.73+1.29$. $\mathrm{PI}_{\max }$ and $\mathrm{PE}_{\max }$ values were normally distributed (Shapiro-Wilkins test).

Table 1 represents the anthropometric variables and pulmonary function test, expressed as the mean and standard deviation, according to age and gender. All the anthropometric variables, physical activity levels through IPAQ, and pulmonary function test values were the same in both the genders; except for specific height, weight and BMI were higher in girls than in boys for 10-, 11- and 12-year old children $(\mathrm{p}<0.05)$. One-way ANOVA tests for age-wise comparison of all the anthropometric variables and pulmonary function test values were increasing across all the age groups $(\mathrm{p}<0.05)$.

Maximal static respiratory pressure values are increasing significantly across all age groups as shown in table 2. One-way ANOVA test showed that $\mathrm{PI}_{\max }$ and $\mathrm{PE}_{\max }$ values increases with the age and are statistically significant $(\mathrm{p}<0.05)$ except for 9 versus 10 age groups for $\mathrm{PI}_{\max }$ and 8 versus 9 age groups for $\mathrm{PE}_{\max }$. The Independent t-test indicated the mean of maximal respiratory strength values tend to be significantly higher in boys than in girls $(\mathrm{p}<0.05)$. Figure 1 represents the smoothed centile curves $\left(3^{\text {rd }}, 10^{\text {th }}, 25^{\text {th }}, 50^{\text {th }}\right.$, $75^{\text {th }}, 90^{\text {th }}$, and $97^{\text {th }}$ percentile) for boys' and girls' values across all age groups for both $\mathrm{PI}_{\max }$ and $\mathrm{PE}_{\max }$. Together, these data show that boys performed better on the test at all the age groups when compared to girls.

Tables 3 and 4 represent the age- and gender-specific centiles of both $\mathrm{PI}_{\max }$ and $\mathrm{PE}_{\max }$. In boys, the $50^{\text {th }}$ percentile values for $\mathrm{PI}_{\max }$ ranged from $49 \mathrm{cmH}_{2} \mathrm{O}$ to $65 \mathrm{cmH}_{2} \mathrm{O}$ and for $\mathrm{PE}_{\max }$ ranged from $51 \mathrm{cmH}_{2} \mathrm{O}$ to $66.5 \mathrm{cmH}_{2} \mathrm{O}$. In girls, the $50^{\text {th }}$ percentile values for $\mathrm{PI}_{\max }$ ranged from $47.5 \mathrm{cmH}_{2} \mathrm{O}$ to $58.5 \mathrm{cmH}_{2} \mathrm{O}$ and for $\mathrm{PE}_{\max }$ ranged from $54 \mathrm{cmH}_{2} \mathrm{O}$ to $62 \mathrm{cmH}_{2} \mathrm{O}$. The values for $\mathrm{PI}_{\max }$ in both the genders suddenly declined 
at $97^{\text {th }}$ percentile for 10- year old age group. In boys, the values were higher across all age groups, with the most apparent gains between the ages of 11 years. In girls, the values were higher between 10-11 years, with the performance values being lower than boys across all the age groups.

\section{Discussion:}

The current study represents the normative values for maximum static respiratory pressure for both $\mathrm{PI}_{\max }$ and $\mathrm{PE}_{\max }$ among a population-based sample of the government schools from Bangalore, India. These results can be utilized as a baseline for long term physical fitness surveillance in the evaluation of the respiratory system function in preschool and school-age children.

Our value of $\mathrm{PI}_{\max }\left(60.83(19.5) \mathrm{cmH}_{2} \mathrm{O}\right)$ was relatively lower by mean of $15.32 \mathrm{cmH}_{2} \mathrm{O}$ when compared from Brazilian ${ }^{5}, 12.2 \mathrm{cmH}_{2} \mathrm{O}$ from Mexican ${ }^{3}$, and $16.23 \mathrm{cmH}_{2} \mathrm{O}$ from Australian ${ }^{24}$ population. Similarly, the mean of $\mathrm{PE}_{\max }$ of the current study $\left(62.26(18.13) \mathrm{cmH}_{2} \mathrm{O}\right)$ was relatively lower by mean of 27.625 $\mathrm{cmH}_{2} \mathrm{O}$ when compared from Brazilian ${ }^{5}, 21.845 \mathrm{cmH}_{2} \mathrm{O}$ from Mexican ${ }^{3}$ and $24.365 \mathrm{cmH}_{2} \mathrm{O}$ from Australian ${ }^{24}$ population. The mean of the current study was also lower in comparison to the study done by Basu et.al. ${ }^{12}$ (boys: $\mathrm{PI}_{\max } 65.6(21.2) \mathrm{cmH}_{2} \mathrm{O}$ and $\mathrm{PE}_{\max }$ 65.3(19.4) $\mathrm{cmH}_{2} \mathrm{O}$ and girls: $\mathrm{PI}_{\max } 66.0(24.0) \mathrm{cmH} 2 \mathrm{O}$ and $\mathrm{PE}_{\max }$ 60.6(22.8) $\mathrm{cmH} 2 \mathrm{O}$ ). The low normative values possibly are due to low socioeconomic status, reduced consumption of vegetables and fruits, a decrease in physical activity, and an increase in sedentary behavior in the children. According to Talib et. al. ${ }^{25}$ and Aslan et.al. ${ }^{26}$, physically active children had increased maximal respiratory pressures.

BMI reflects the body fat distribution in terms of the nutritional level of the child and has shown an influence on respiratory muscle strength ${ }^{33}$. The mean BMI of the current population falls in the underweight category with mean $17.23 \mathrm{Kgm}^{-2}$ in boys and $17.65 \mathrm{kgm}^{-2}$ in girls. The reduced BMI may be associated with reduced skeletal muscle mass. The diaphragmatic muscle, which is the primary muscle of inspiration along with intercostal and abdominal muscle mass, has shown to have low muscle mass leading to reduced respiratory muscle strength in children ${ }^{27,28}$.

Physical activity levels have shown to be directly influencing respiratory muscle strength. ${ }^{25}$ The current study observed that the physical activity levels decreased with advancing age in boys contrasting with increasing levels of physical activity in girls. The children in the current study achieved only mild-moderate levels of physical activity, in comparison to the recommended levels of physical activity by WHO (60 minutes of moderate-vigorous activity daily $)^{29}$. This could be due to less walking and increased dependence on vehicles for transport and reduced participation in games leading to a reduction in the respiratory muscle strength ${ }^{30}$. An earlier study quoted that $52 \%$ of the children achieved a moderate-vigorous level of $\mathrm{PA}^{31}$, while, Indian children do not achieve recommended levels of $\mathrm{PA}^{30}$.

Similarly, physical activity and aerobic fitness are positively associated with lung volumes ${ }^{32}$. The current study has shown the mean values of $\mathrm{FEV}_{1}, \mathrm{FVC}$, and $\mathrm{FVC} / \mathrm{FEV}_{1}$ in the current study are $1.06 \mathrm{~L}, 1.45 \mathrm{~L}$, and $73 \%$ in boys and $1.04 \mathrm{~L}, 1.42 \mathrm{~L}$ and $73 \%$ in girls, respectively and are increasing with increasing age in both the genders. Although, the mean of the lung volumes is reported to be lower when compared to previously published studies ${ }^{1,33,34}$. The current study exhibits lower BMI and increased sedentary lifestyle which could have possibly lead to a reduction in muscle mass owing to reduced overall physical fitness which has seen to have negatively impacted the lung volumes and capacities ${ }^{35}$.

The result of the present study is showing the normative data of $\mathrm{PI}_{\max }$ and $\mathrm{PE}_{\max }$ in the current population. The $50^{\text {th }}$ percentile values of $\mathrm{PI}_{\max }$ ranged from $49 \mathrm{cmH}_{2} \mathrm{O}$ to $65 \mathrm{cmH}_{2} \mathrm{O}$ and for $\mathrm{PE}_{\max }$ ranged from 51 $\mathrm{cmH}_{2} \mathrm{O}$ to $66.5 \mathrm{cmH}_{2} \mathrm{O}$ in boys. Similarly, in girls, the $50^{\text {th }}$ percentile values for $\mathrm{PI}_{\text {max }}$ ranged from 47.5 $\mathrm{cmH}_{2} \mathrm{O}$ to $58.5 \mathrm{cmH}_{2} \mathrm{O}$ and for $\mathrm{PE}_{\max }$ ranged from $54 \mathrm{cmH}_{2} \mathrm{O}$ to $62 \mathrm{cmH}_{2} \mathrm{O}$. These findings can be utilized to compare the values between the countries, as a medium of physical fitness in the evaluation of the respiratory muscle strength among children.

There are several limitations in the current study like body mass index can be evaluated using standardized equipment for accuracy and objective evaluation of physical activity levels. Therefore, we suggest studies 
can be done to investigate whether the level of physical activity and socioeconomic factors may be significant predictors of respiratory muscle strength in children.

Thus, the study proposes the age- and gender-specific normative values for maximal static respiratory pressures for a large, population-based sample of school-going children aged 8-12 years from Bangalore, India. The mean and standard deviation for $\mathrm{PI}_{\max }$ is $57.84(17.83) \mathrm{cmH}_{2} \mathrm{O}$ in boys and $53.82(16.11) \mathrm{cmH}_{2} \mathrm{O}$ in girls and for $\mathrm{PE}_{\max }$, the mean and standard deviation is $60.02(18.12) \mathrm{cmH}_{2} \mathrm{O}$ in boys and $56.42(16.75) \mathrm{cmH}_{2} \mathrm{O}$ in girls aged 8-12 years from Bangalore, India.

\section{Acknowledgments:}

We would like to thank the government officials of Bangalore for permitting the approach to schools in the city of Bangalore, India. We would also like to thank the primary educators from the school for permitting to conduct the study within the school premises and the parents for giving consent for their children to participate in the study. Finally, we would like to thank all the children for keeping patience, co-operating, and volunteering to participate in this study.

Conflict of interest: None

\section{References:}

[1] Heinzmann-Filho JP, Vidal PC, Jones MH, Donadio MV. Normal values for respiratory muscle strength in healthy preschoolers and school children. Respir Med 2012;106(12):1639-46.

[2] Delgado RN, Campos TF, de Oliveira Borja R, de Freitas DA, da Silva Chaves GS, de Mendonça KM. Maximal respiratory pressures of healthy children: comparison between obtained and predicted values. Pediatr Phys Ther 2015;27(1):31-7.

[3] Lanza FC, de Moraes Santos ML, Selman JP, Silva JC, Marcolin N, Santos J, Oliveira CM, Dal Lago P, Dal Corso S. Reference equation for respiratory pressures in pediatric population: a multicenter study. PloS one $2015 ; 10(8)$ e 0135662 .

[4] Hulzebos E, Takken T, Reijneveld EA, Mulder MM, Bongers BC. Reference values for respiratory muscle strength in children and adolescents. Respiration 2018;95(4):235-43.

[5] Mendes RE, Campos TF, Macêdo TM, Borja RO, Parreira VF, Mendonça KM. Prediction equations for maximal respiratory pressures of Brazilian adolescents. Braz J Phys Ther 2013;17(3):218-26.

[6] Wagener JS, Hibbert ME, Landau LI. Maximal respiratory pressures in children. Am Rev Respir Dis 1984;129(5):873-5.

[7] Szeinberg A, Marcotte JE, Roizin H, Mindorff C, England S, Tabachnik E, Levison H. Normal values of maximal inspiratory and expiratory pressures with a portable apparatus in children, adolescents, and young adults. Pediatr Pulmonol 1987;3(4):255-8.

[8] Tomalak W, Pogorzelski A, Prusak J. Normal values for maximal static inspiratory and expiratory pressures in healthy children. Pediatr Pulmonol 2002;34(1):42-6.

[9] Domènech-Clar R, López-Andreu JA, Compte-Torrero L, De Diego-Damiá A, Macián-Gisbert V, PerpiñáTordera M, Roque's-Serradilla JM. Maximal static respiratory pressures in children and adolescents. Pediatr Pulmonol 2003;35(2):126-32.

[10] Wilson SH, Cooke NT, Edwards RH, Spiro SG. Predicted normal values for maximal respiratory pressures in Caucasian adults and children. Thorax 1984;39(7):535-8.

[11] Gaultier C, Zinman R. Maximal static pressures in healthy children. Respir Physiol 1983;51(1):45-61.

[12] Basu K, Saha C, Bhattacharyya N, Sabui T, Mukherjee DK, Ogston SA, Mukopadhay S. Respiratory muscle function in healthy school children from Kolkata, India. Arch Dis Child 2012;97(1): 44. 
[13] Gopalakrishna A, Vaishali K, Prem V, Aaron P. Normative values for maximal respiratory pressures in an Indian Mangalore population: A cross-sectional pilot study. Lung India 2011;28(4):247-52.

[14] Guthold R, Cowan MJ, Autenrieth CS, Kann L, Riley LM. Physical activity and sedentary behavior among schoolchildren: a 34-country comparison. J Pediatr 2010;157(1):43-9.

[15] Katzmarzyk PT, Barreira TV, Broyles ST, Champagne CM, Chaput JP, Fogelholm M, Hu G, Johnson WD, Kuriyan R, Kurpad A, Lambert EV. The international study of childhood obesity, lifestyle and the environment (ISCOLE): design and methods. BMC public health 2013;13(1):900.

[16] Saloheimo T, González SA, Erkkola M, Milauskas DM, Meisel JD, Champagne CM, Tudor-Locke C, Sarmiento O, Katzmarzyk PT, Fogelholm M. The reliability and validity of a short food frequency questionnaire among 9-11-year olds: a multinational study on three middle-income and high-income countries. Int J Obes Suppl 2015;5(2): S22-8.

[17] Cecilia SP, Paulo VM, Geraldo AN. Comparison of direct and indirect methods for Determination of the Maximal Oxygen Uptake in females' runners. Rev Bras Med Esporte 2011;17(1): 270-273.

[18] Craig CL, Marshall AL, Sjöström M, Bauman AE, Booth ML, Ainsworth BE, Pratt M, Ekelund UL, Yngve A, Sallis JF, Oja P. International physical activity questionnaire: 12-country reliability and validity. Med Sci Sports Exerc 2003;35(8):1381-95.

[19] Regaieg S, Charfi N, Yaich S, Damak J, Abid M. The reliability and concurrent validity of a modified version of the international physical activity questionnaire for adolescents (IPAQ-A) in Tunisian overweight and obese youths. Med Princ Prac 2016;25(3):227-32.

[20] Zhang H, Li L, Jiao D, Yang Y, Pan C, Ye L, Wei S, Jin M. An Interrater Reliability Study of Pulmonary Function Assessment with a Portable Spirometer. Respir Care 2020;65(4) 665-672.

[21] Miller MR. ATS/ERS task force: standardization of spirometry. Eur Respir J. 2005; 26:319-38.

[22] European RS, American Thoracic Society. ATS/ERS Statement on respiratory muscle testing. Am J Respir Crit Care Med 2002;166(4):518-624.

[23] Dimitriadis Z, Kapreli E, Konstantinidou I, Oldham J, Strimpakos N. Test/retest reliability of maximum mouth pressure measurements with the MicroRPM in healthy volunteers. Respiratory care 2011;56(6):77682.

[24] Cox DW, Verheggen MM, Stick SM, Hall GL. Characterization of maximal respiratory pressures in healthy children. Respiration 2012;84(6):485-91.

[25] Talib N, Gaillard E, Viskaduraki M, Beardsmore C. Does physical activity affect respiratory muscle strength? ERJ 2016:48:PA1219

[26] Aslan GK, Akinci B, Yeldan I, Okumus G. Respiratory muscle strength in patients with pulmonary hypertension: the relationship with exercise capacity, physical activity level, and quality of life. Clin Respir J 2018;12(2):699-705.

[27] Park CH, Yi Y, Do JG, Lee YT, Yoon KJ. Relationship between skeletal muscle mass and lung function in Korean adults without clinically apparent lung disease. Medicine. 2018;97(37):e12281

[28] Lewis MI, Sieck GC, Fournier MA, Belman MJ. Effect of nutritional deprivation on diaphragm contractility and muscle fiber size. J Appl Physiol 1986;60(2):596-603.

[29] Janssen I, LeBlanc AG. Systematic review of the health benefits of physical activity and fitness in school-aged children and youth. Int J Behav Nutr Phys Act. 2010;7(1):40.

[30] Katapally TR, Goenka S, Bhawra J, Mani S, Krishnaveni GV, Kehoe SH, Lamkang AS, Raj M, McNutt K. Results from India's 2016 report card on physical activity for children and youth. J Phys Act Health 2016;13(s2):S176-82. 
[31] Ronghe DR, Gotmare DN, Kawishwar DS. Physical activity level of school children of age 10-13 years. IJBAR 2016;7(6):281-285.

[32] Hancox RJ, Rasmussen F. Does physical fitness enhance lung function in children and young adults? ERJ 2018;51(2):1701374.

[33] Mafort TT, Rufino R, Costa CH, Lopes AJ. Obesity: systemic and pulmonary complications, biochemical abnormalities, and impairment of lung function. Multidiscip Respir Med 2016;11(1):28.

[34] da Rosa GJ, Schivinski CI. Avaliacao da forca muscular respiratoria de criancas segundo a classificacao do indice de massa corporal. Revista Paulista de Pediatria. 2014;32(2):250-5.

[35] Do JG, Park CH, Lee YT, Yoon KJ. Association between underweight and pulmonary function in 282,135 healthy adults: A cross-sectional study in Korean population. Sci Rep 2019;9(1):1-0.

\section{Hosted file}

Table_1_2_3_4_Manuscript.docx available at https://authorea.com/users/328596/articles/455796normative-value-of-maximal-static-respiratory-pressures-in-healthy-children-between-agegroup-8-12-years

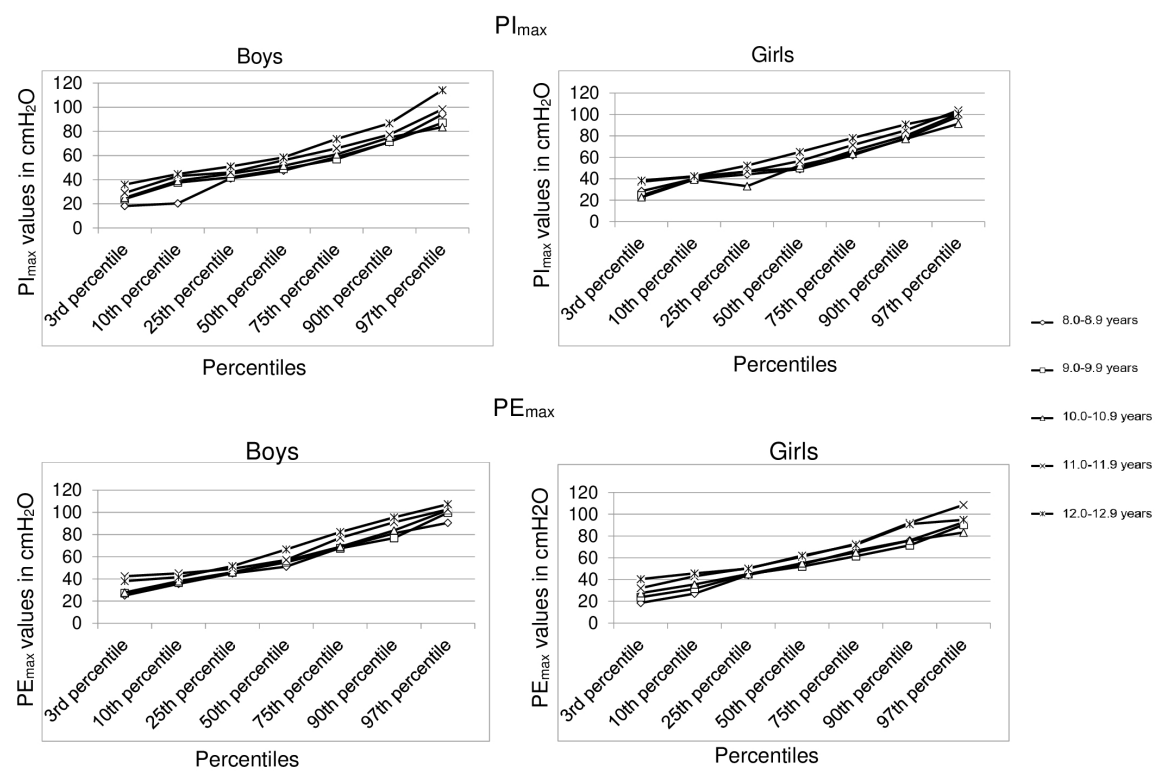

Figure 1: Smoothed centile curves for maximal inspiratory $\left(\mathrm{PI}_{\max }\right)$ and expiratory $\left(\mathrm{PE}_{\max }\right)$ pressures 